\title{
Identifying Chemokines as Therapeutic Targets in Renal Disease: Lessons from Antagonist Studies and Knockout Mice
}

\author{
Volker Vielhauer Vaclav Eis Detlef Schlöndorff Hans-Joachim Anders \\ Medizinische Poliklinik Innenstadt, Klinikum der Universität München, Ludwig Maximilians University, Munich, \\ Germany
}

\author{
Key Words \\ Chemokine - Leukocyte recruitment · Kidney • \\ Inflammation · Renal failure · Transplantation
}

\begin{abstract}
Chemokines, in concert with cytokines and adhesion molecules, play multiple roles in local and systemic immune responses. In the kidney, the temporal and spatial expression of chemokines correlates with local renal damage and accumulation of chemokine receptor-bearing leukocytes. Chemokines play important roles in leukocyte trafficking and blocking chemokines can effectively reduce renal leukocyte recruitment and subsequent renal damage. However, recent data indicate that blocking chemokine or chemokine receptor activity in renal disease may also exacerbate renal inflammation under certain conditions. An increasing amount of data indicates additional roles of chemokines in the regulation of innate and adaptive immune responses, which may adversively affect the outcome of interventional studies. This review summarizes available in vivo studies on the blockade of chemokines and chemokine receptors in kidney diseases, with a special focus on the therapeutic potential of anti-chemokine strategies, including potential side effects, in renal disease.
\end{abstract}

Copyright $(2004$ S. Karger AG, Basel

\section{KARGER}

Fax +41613061234

www. karger.com
E-Mail karger@karger.ch

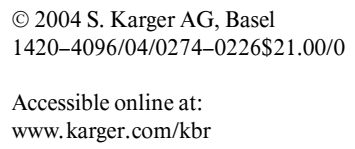

\section{Introduction}

Generally, immune responses are mediated by immune cells that are activated before they contribute to immunity. Immune cell activation is mediated and regulated by a variety of factors including lipid mediators, immunoglobulins, adhesion molecules, and cytokines. The superfamily of cytokines includes several families of chemotactic cytokines, i.e. the chemokines, which mediate cell activation via transmembrane surface receptors on target cells. To facilitate immune cell recruitment and activation, chemokines are released locally by parenchymal cells as well as by infiltrating cells in injured organs. Chemokines have a prominent role in leukocyte migration to sites of tissue injury [1-5], but they also have many other additional functions that contribute to immunity and tissue homeostasis. These include homeostatic functions in leukocyte development, cell trafficking during immune surveillance, hematopoiesis, and angiogenesis [6-10]. In the context or renal inflammation, most studies and recent reviews have focused on the role of chemokines in the recruitment of immune cells into diseased kidneys [11-13]. However, unexpected data from studies with chemokine antagonists and from mice genetically deficient for chemokines or chemokine receptors have raised new questions about additional roles of chemokines in the inflammatory process. In this review we pro-
Volker Vielhauer, MD

Medizinische Poliklinik Innenstadt, Ludwig Maximilians University

Pettenkoferstrasse 8a

DE-80336 Munich (Germany)

Tel. +498951603500, Fax +498951604439, E-Mail V.Vielhauer@lrz.uni-muenchen.de 
vide a brief introduction on chemokine biology and then focus on potentially confounding effects of chemokines in renal disease which have to be considered for future research in this field.

\section{The Chemokine Superfamily}

Chemokines are a family of low-molecular-weight cytokines first characterized by their ability to induce directed migration of leukocytes [1-3]. Although chemokines have a relatively low level of sequence identity, their three-dimensional structure is highly homolog in that they all have the same monomeric fold. This fold results from a four-cysteine motif that forms two characteristic disulfide bridges. Depending on the relative position of the first two cysteines, chemokines are divided into CC, CXC, C, and $\mathrm{CX} 3 \mathrm{C}$ subfamilies [6]. The systematic nomenclature describes individual chemokines (ligands L) and their receptors $(\mathrm{R})$ on the basis of subgroups they belong to (fig. 1) $[6,14]$. Chemokines can be further categorized into two classes depending on whether they are constitutively produced or are inducible $[10,15]$. The first group, the homeostatic chemokines, are instrumental in basal leukocyte development and trafficking during immune surveillance. In contrast, inflammatory chemokines are induced by proinflammatory stimuli and orchestrate innate and adaptive immune responses, for example by recruitment of leukocytes to sites of tissue injury and regulation of $\mathrm{T}$ cell, monocyte and dendritic cell differentiation.

\section{Chemokine Receptors}

All chemokines signal through G-protein-coupled seven-transmembrane receptors. Chemokine receptors are named and classified according to their chemokine ligand(s), that is $\mathrm{C}, \mathrm{CC}, \mathrm{CXC}$, and $\mathrm{CX} 3 \mathrm{C}$ receptors (fig. 1) $[6,14]$. Each chemokine receptor has a distinct chemokine specificity and a restricted expression on subclasses of leukocytes (and non-hematopoietic cells). However, ligand specificities of the receptors can substantially overlap within a chemokine class leading to redundancy in the system. Some receptors bind multiple chemokines, and others share the same ligands (fig. 1). In general, the proinflammatory chemokine receptors have more promiscuous ligand-binding specificities, while receptors involved in basal leukocyte development and trafficking have fewer ligands. Although in vitro binding and activa- tion studies suggest a high degree of redundancy in the chemokine system, this might actually be not true in vivo. Indeed, genetic and an increasing number of functional studies have largely confirmed that single chemokines and receptors play non-redundant roles in immune biology $[15,16]$. The complexity of the system may be further enhanced by the fact that chemokine receptors can form heterodimers with new ligand specificities and that some chemokines or their metabolites can even act as antagonists for their receptors [17]. This seemingly confusing system allows for highly adaptable and dynamic responses.

\section{Chemokines Regulate Leukocyte Trafficking}

Leukocyte extravasation from the blood into the tissues is a highly regulated and selective process, involving multiple ligand receptor interactions between the circulating leukocyte and endothelial cells. A multistep paradigm was developed that describes discrete stages of this interaction [18, 19]. Through transient interactions between selectins and selectin ligands (adressins), a reversible rolling of leukocytes along the endothelial wall is induced [20, 21]. During this rolling phase, leukocytes are brought in contact with chemokines that are retained on heparan sulfate proteoglycans of the endothelial surface following secretion by activated endothelial cells, activated platelets, and subendothelial parenchymal cells. Chemokine signaling through specific, leukocyte-expressed G-protein-coupled receptors activates integrins, resulting in irreversible firm adhesion of the leukocyte to the endothelial surface, where integrin ligands, the intercellular adhesion molecules of the immunoglobulin superfamily, are expressed [5, 22, 23]. This arrest is the prerequisite allowing subsequent spreading, diapedesis, and transmigration of the leukocyte into the inflamed tissue. Thus, chemokine signaling converts the low-affinity, selectin-mediated leukocyte-endothelial cell interaction into the high-affinity, integrin-mediated interaction that leads to extravasation of leukocytes. Different chemokines and chemokine receptors appear involved during the initial leukocyteendothelial interaction and the subsequent transendothelial migration [16]. Therefore, expression of a chemokine in a tissue and the presence of its receptor on a circulating leukocyte substantially contribute to the selectivity of the local leukocyte recruitment. 
Fig. 1. Chemokines and chemokine receptors. Abbreviations are: $\mathrm{i}=$ inflammatory; $\mathrm{h}=$ homeostatic. The abbreviations of the common names are as follows: GCP-2 = granulocyte chemotactic protein-2; IL-8 = interleukin-8; Gro = growth-regulated oncogene; $\mathrm{KC}=$ keratinocyte-derived chemokine; MIP = macrophage inflammatory protein; $\mathrm{CINC}=$ cytokine-induced neutrophil chemoattractant; ENA78 = epithelial cell-derived neutrophil-activating peptide 78; NAP-2 = neutrophil-activating peptide-2; PF4 = platelet factor $4 ; \mathrm{MIG}=$ monokine induced by interferon- $\gamma$; IP-10 $=$ interferoninducible protein-10; I-TAC $=$ interferoninducible T-cell $\alpha$ chemoattractant; SDF-1 = stromal cell-derived factor-1; BCA-1 = $\mathrm{B}$ cell-attracting chemokine-1; BRAK = breast and kidney-expressed chemokine; SR-PSOX = scavenger receptor for phosphatidylserine and oxidized lipoprotein; RANTES = regulated on activation, normal T-cell expressed and secreted; $\mathrm{MCP}=$ monocyte chemoattractant protein; MPIF = myeloid progenitor inhibitory factor; $\mathrm{HCC}=$ hemofiltrate $\mathrm{CC}$ chemokine; TARC $=$ thymus and activationregulated chemokine; $\mathrm{MDC}=$ macrophagederived chemokine; DC-CK1 = dendritic cell chemokine 1 ; LARC $=$ liver and activation-regulated chemokine; ELC = EBI1 ligand chemokine; SLC = secondary lymphoid tissue chemokine; TCA-3 = T-cell activation protein-3; TECK = thymus-expressed chemokine; CTACK = cutaneous T-cell-attracting chemokine; ESkine = embryonic stem cell-derived chemokine; MEC $=$ mucosaeassociated epithelial chemokine; SCM- $1 \beta=$ single cysteine motif- $1 \beta$ chemokine.

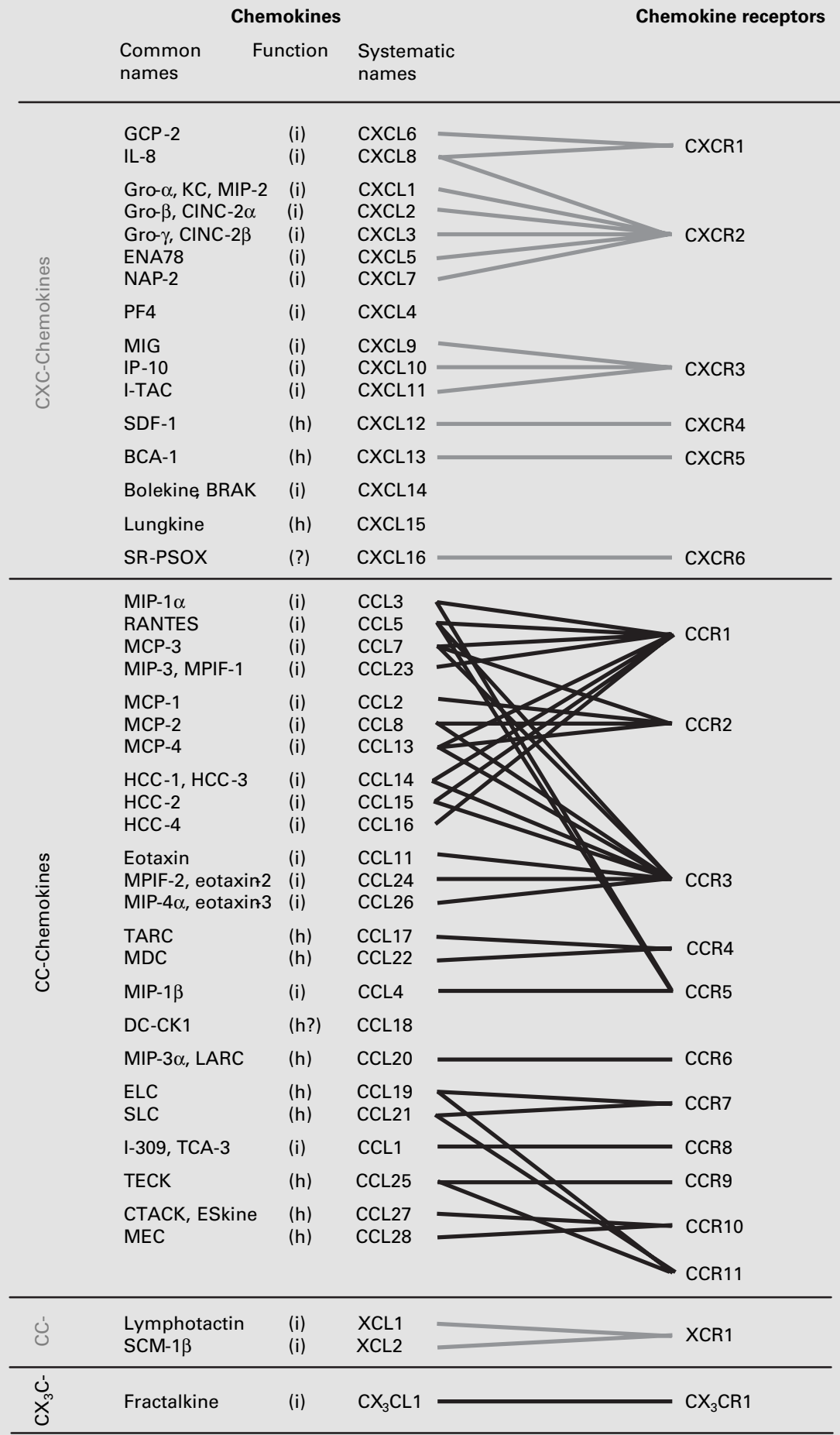




\section{Chemokines Have Multiple Other Functions in Local and Systemic Immune Responses}

In addition to their role in leukocyte trafficking, chemokines play important roles in innate and adaptive immune responses. This includes leukocyte activation, dendritic cell function, lymphocyte function during immune surveillance and response, lymphocyte maturation and differentiation, and hematopoiesis and angiogenesis $[2,3,6-10]$.

Chemokines stimulate leukocyte degranulation or release of inflammatory mediators. For example, CXCL8/ interleukin (IL)-8 stimulates neutrophil degranulation, and CCL2/MCP-1 is a potent stimulator of histamine release by basophils [3]. Moreover, chemokines, like CXCL8/IL-8 and CCL5/RANTES, induce respiratory burst in granulocytes and macrophages leading to the local production of reactive oxygen species [3]. CCL5/ RANTES has also been shown to costimulate T-lymphocyte activation [24].

Cell migration and positioning is central at diverse phases of the adaptive immune response, hence chemokines and their receptors are critically involved in many aspects of adaptive immunity. A number of studies have shown that the ability of dendritic cells to migrate into inflamed tissue and then to the draining lymph node for antigen presentation is based on differential chemokine receptor expression on the dendritic cell $[3,6]$. Immature dendritic cells express receptors for inflammatory chemokines such as CCR1, CCR2, CCR5, and CCR6, which are then downregulated as the cells mature. Mature dendritic cells upregulate expression of lymphoid-homing chemokine receptors such as CCR7, guiding them to lymph nodes, where the CCR7 ligands CCL19/ELC and CCL21/ SLC are expressed [3, 6].

Within lymphoid tissue, the complex cellular interaction between naive $\mathrm{T}$ and dendritic cells or between $\mathrm{T}$ and B cells are also controlled by chemokines [3, 6, 25]. Naive $\mathrm{T}$ cells express CCR7, that facilitates their location to lymphoid tissue during immune surveillance. In contrast, subsets of effector and memory $\mathrm{T}$ cells express proinflammatory chemokine receptors like CCR2, CCR3, CCR5, CCR6, CCR8 or CXCR5, that facilitate recruitment into inflamed non-lymphoid tissue during the effector phase or positioning within lymph node follicles for generation of antibody producing B-cells. Mature B cells uniformly express CXCR5 and migrate into follicles in response to the CXCR5 ligand CXCL13/BCA-1 [3, 6, 25].

Chemokines also regulate effector T-cell differentiation [7]. For example, CCL2/MCP-1-deficient mice have diminished Th2 responses and their T cells do not secrete IL-4, IL-5 and IL-10, although IFN- $\gamma$ and IL-2 production are unaffected. These mice cannot achieve the immunoglobulin E subclass switch that is characteristic for Th2 responses and are more resistant to Th2-associated disease [26]. Conversely, a positive regulatory effect on Th1 cell differentiation has been suggested for CCR5 and its ligands CCL3/MIP-1 $\alpha$, CCL4/MIP-1 $\beta$, and CCL5/ RANTES by inducing expression of IL-12 by antigen-presenting cells and by directly polarizing Th cells to secrete IFN- $\gamma$ [7]. Moreover, a number of chemokine receptor associations with the Th1 and Th2 phenotype have been reported. While CCR 1, CCR 5 and CXCR 3 are expressed on Th1 cells, CCR3, CCR4, and CCR 8 have been associated with the Th2 phenotype $[6,7]$. This allows a differential recruitment of Th1 or Th2 cells to sites of inflammation, where chemokines are often differentially induced in response to different pathogens and stimuli.

\section{Expression of Chemokines by Activated Renal Cells}

All types of intrinsic renal cells including endothelial cells, podocytes, mesangial cells, tubular epithelial cells, and interstitial fibroblasts can produce inflammatory chemokines upon stimulation [reviewed in 12]. In vitro studies demonstrated that chemokine production of all types of renal cells is induced by proinflammatory stimuli such as reactive oxygen species, cytokines (TNF- $\alpha$, IL- $1 \beta$, IFN- $\gamma$ ), vasoactive substances like angiotensin II, and pathogen-associated molecules such as lipopolysaccharide [12]. Subsequently, infiltrating leukocytes are a major source of local chemokine production in the kidney, for example MIP- $1 \alpha$ seems to be exclusively produced by infiltrating macrophages [27-30]. A positive amplification loop is formed, as chemokines secreted by infiltrating leukocytes promote further local leukocyte recruitment and activation.

\section{Association of Chemokine Expression with Renal Injury}

Several studies have localized the expression of chemokines in animal models of glomerular and tubulointerstitial disease by in situ hybridization and immunohistochemistry [reviewed in 13]. For example, expression of CCL2/MCP-1 and CCL5/RANTES localized to intrinsic renal cells and infiltrating leukocytes confirming the in 
vitro data mentioned earlier. Expression of various inflammatory chemokines is generally restricted to the injured compartment of the kidney $[12,13]$. In acute immune complex glomerulonephritis, chemokines are exclusively produced within glomeruli $[27,31]$, whereas in interstitial nephritis induced by unilateral ureteral obstruction, chemokine expression is confined to the interstitial compartment [28]. When progression of a glomerular disease leads to secondary tubulointerstitial damage, chemokines are produced in both diseased compartments, for example during murine lupus nephritis [32, 33]. Moreover, the spatial expression of chemokines correlates with local accumulation of chemokine receptorpositive leukocytes at sites of renal damage [27, 28, 33].

Chemokines are involved both in the initiation and progression of renal disease [reviewed previously in detail in 13]. On the one hand, termination of the chemokine signal is critical for the resolution of the inflammatory process [27]. On the other hand, when local chemokine expression is augmented and prolonged by additional proinflammatory stimuli that may be independent of the initial injury, the ongoing recruitment of inflammatory cells leads to accelerated progression of a preexisting renal disease towards severe renal damage with loss of organ function $[34,35]$. Thus, even if the initial injury to the kidney subsides, chemokine-mediated leukocyte recruitment can be maintained or, in the case of a chronic disease process, exacerbated by other mechanisms such as infection, activation of the renin-angiotensin system, hypoxia, and proteinuria $[34,35]$.

Taken together, these observations support the concept that chemokines, locally produced by intrinsic renal cells and infiltrating inflammatory cells, are involved in mediating local immunity such as renal leukocyte recruitment and inflammation. Importantly, the relevance of the animal data for human disease has been confirmed by various human biopsy studies that demonstrated similar expression patterns of chemokines and chemokine receptors in relation to renal leukocyte infiltration and tissue damage [36-43].

\section{Chemokines in Glomerulonephritis}

The functional roles of chemokines in the pathogenesis of acute glomerulonephritis have been demonstrated in various animal models by blocking chemokine activity with neutralizing antibodies, chemokine receptor antagonists, and targeted disruption of chemokine and chemokine receptor genes $[12,13]$. However, some of these stud- ies yielded conflicting results illustrating the multifaceted roles of chemokines in leukocyte trafficking and immune responses.

\section{Chemokines Mediate Glomerular Leukocyte \\ Recruitment}

Several studies utilized the nephrotoxic serum nephritis model in the rat and mouse. In the rat, neutralizing antibodies to CXC chemokines, including CXCL1/MIP-2 and CINC, reduced glomerular neutrophil infiltration and proteinuria during the acute phase of the model [29, 44, 45]. Blockade of the CXC chemokine receptor CXCR2, which binds multiple CXC chemokines including CXCL1/MIP-2 and CINC, with the peptide analog Gro- $\alpha_{8-73}$, demonstrated a role of CXCR2 in mediating glomerular monocyte recruitment in the rat nephrotoxic nephritis model [46]. Inhibition of multiple CC and CXC chemokine receptors by vMIP-II, a viral broad chemokine antagonist encoded by human herpesvirus 8 , also decreased proteinuria and glomerular infiltration of macrophages and $\mathrm{CD}^{+} \mathrm{T}$ cells in rats [47]. Blocking the $\mathrm{CX}_{3} \mathrm{CL} 1 /$ fractalkine receptor $\mathrm{CX}_{3} \mathrm{CR} 1$ with a neutralizing antibody improved renal function and prevented crescentic glomerulonephritis in rat nephrotoxic nephritis [48]. In the same model, antibody blockade of the CC chemokine CCL22/macrophage-derived chemokine reduced glomerular macrophage influx, prevented crescent formation, and reversed renal functional impairment [31].

\section{Targeting CCL2/MCP-1 and Its Receptor CCR2 \\ Yields Conflicting Results in Antagonist Studies and \\ Knockout Mice}

Neutralizing antibodies to the CC chemokine CCL2/ MCP-1, a major monocyte/macrophage chemoattractant, blocked glomerular infiltration of macrophages in the rat anti-Thy-1.1 nephritis model [49]. Treatment with antiCCL2/MCP-1 antibodies also reduced glomerular macrophage influx and proteinuria in rat nephrotoxic serum nephritis [50-52] and abrogated glomerular and interstitial leukocyte infiltration, proteinuria, crescent formation and interstitial collagen deposition in murine nephrotoxic nephritis [53]. Consistently, a preliminary report demonstrated that blockade of the CCL2/MCP-1 receptor CCR2 with a series of novel antagonists ameliorated disease, including glomerular injury, in the rat model [54]. Tubulointerstitial damage but not glomerular histopathology was reduced in rats with nephrotoxic serum nephritis when CCL2/MCP-1 expression was selectively blocked in tubular epithelial cells by an antisense approach [55]. These studies clearly support a functional role of CCL2/ 
MCP-1 signaling in experimental glomerulonephritis. Surprisingly, however, contradictory results have been obtained in mice with targeted gene deletion of CCL2/ MCP-1 and CCR2. In CCL2/MCP-1-deficient mice with nephrotoxic serum nephritis, glomerular injury and proteinuria were comparable to wild-type mice, and only the tubulointerstitial injury was reduced [56]. Moreover, in mice lacking CCR2, the proteinuria and glomerular pathology of nephrotoxic serum nephritis was worse, despite reduced glomerular macrophage infiltration [57]. Although compensatory chemokine and chemokine receptor systems may develop in genetically deficient mice, the discrepant results have important implications. In view of their roles in adaptive immunity, targeting CCL2/MCP-1 and CCR2 in acute glomerulonephritis may not simply interfere with renal leukocyte recruitment and activation, but may fundamentally alter the systemic immune response that subsequently causes the glomerular injury, for example by augmenting Th1 effector mechanisms. As discussed earlier, CCL2/MCP-1-deficient mice have diminished cellular and humoral Th2 responses. Moreover, CCL2/CCR2 signaling may be important to activate CCR2-positive regulatory $\mathrm{T}$ cells, which are essential to downregulate adaptive immune responses (see below).

Blockade of the CCL5/RANTES Receptors Can Have Beneficial and Adverse Effects in Glomerulonephritis

Beneficial effects of two CCL5/RANTES analogs, amino-oxypentane (AOP)-RANTES and Met-RANTES, which block binding of human CCL5/RANTES to its receptors CCR1, CCR3, and CCR5, have been demonstrated in rodent studies. AOP-RANTES inhibited glomerular macrophage infiltration and collagen IV deposition in the anti-Thy-1.1 model [58]. Lloyd et al. [53] showed that Met-RANTES reduced glomerular and interstitial leukocyte infiltration and proteinuria in murine nephrotoxic serum nephritis, although glomerular crescent formation and renal collagen deposition was not effected. However, the antagonists Met-RANTES and AOP-RANTES both aggravated glomerular damage and proteinuria in a murine model of acute immune-complex glomerulonephritis, despite reduction of glomerular macrophage infiltration [59]. This was associated with an enhanced proinflammatory state of the macrophages present in the glomerulus, indicated by increased inducible NO synthetase expression and reduced uptake of apoptotic cells [59]. The effect of CCL5/RANTES antagonists on apoptotic cell uptake is of special interest and is another indication of yet poorly understood roles of chemokines. Thus, despite effectively blocking glomeru- lar leukocyte recruitment, Met-RANTES and AOPRANTES altered the phenotype of the resident macrophages, possibly due to agonistic effects on the CCL5/ RANTES receptors, which have been described for these CCL5/RANTES analogs [60]. As mentioned, the CCL5/ RANTES antagonist Met-RANTES reduced leukocyte infiltration and proteinuria in mice with nephrotoxic nephritis [53]. However, disease was not ameliorated in mice deficient for the CCL5/RANTES receptor CCR5 [61], although this may be explained by compensatory utilization of other CCL5/RANTES receptors. Importantly, CCR1-deficient mice developed more severe glomerular pathology, greater proteinuria and an increased renal infiltration of macrophages and $\mathrm{T}$ cells during nephrotoxic nephritis [62]. Interestingly, enhanced Th1 responses were noted in these mice, again suggesting an altered systemic immune response in the effector phase as a potential mechanism of exacerbation [62].

Taken together, these data add to the growing evidence that chemokines do not only promote renal leukocyte recruitment and activation, but also modulate the systemic immune response and the phenotype of infiltrating cells during renal inflammation. Consequently, blockade of specific chemokines or chemokine receptors may potentially induce adverse reactions rather than reduce renal injury, especially in primarily immune-mediated renal disease. Importantly, with systemic immune responses and potential compensatory pathways differentially affected, functional studies in knockout mice and transient blockade of chemokines with antibodies or antagonists can yield different and in part conflicting results. This will be greatly influenced by the type of disease model investigated, and will be less likely in models that involve innate effector mechanisms (like the heterologous phase of the nephrotoxic serum nephritis), as in those requiring an adaptive immune response (like the nephrotoxic nephritis in its autologous phase).

\section{Chemokines in Acute Renal Failure}

Although most functional studies used experimental models of immune-mediated renal disease, a role of chemokines and chemokine receptors in the pathogenesis of acute renal failure has been demonstrated [63]. In renal ischemia-reperfusion injury, neutralizing antibodies to the CXC chemokines CXCL1/Gro- $\alpha$ and MIP-2 blocked interstitial neutrophil infiltration, reduced renal damage and improved survival of treated mice [64]. Furuichi et al. [65] showed that CCR2-deficient mice subjected to renal 
ischemia-reperfusion injury had reduced interstitial macrophage infiltrates and less tubular necrosis than wildtype mice. Moreover, ischemia-reperfusion injury and macrophage infiltration decreased when mice were transfected with the gene construct 7ND that encodes a truncated CCL2/MCP-1 protein and blocks activation of CCR2 by all of its endogenous ligands including CCL2/ MCP-1, CCL7/MCP-3, CCL8/MCP-2, and CCL13/ MCP-4 [66]. These studies indicate that chemokines play a functional role in acute non-immune-mediated renal injury. Blockade of the CXC chemokine-dependent interstitial neutrophil influx or CCL2/CCR2-mediated macrophage infiltration may be a valuable therapeutic strategy in acute renal failure. However, there is growing evidence that lymphocytes also play important roles in primarily non-immune-mediated renal disease such as ischemiareperfusion injury $[67,68]$. Thus, chemokine blockade in this setting may have unforeseen effects by modulating components of the adaptive immune response. This must be carefully considered before therapeutic strategies are applied in humans.

\section{Chemokines in Renal Transplant Rejection}

Because of the predominant cell-mediated immune response, transplantation would appear as an ideal target for chemokine blockade in a therapeutic modality. In a rabbit model of acute renal allograft rejection, renal function and tubulointerstitial damage improved when the CC chemokine receptor CCR1 was blocked with the small peptide antagonist BX471 [69]. In rat models of acute renal allograft rejection, treatment with the CCL5/ RANTES antagonist Met-RANTES significantly reduced vascular and tubular damage, and suppressed mononuclear cell infiltration associated with acute rejection [70]. These results were expanded on in a recent study where treatment with Met-RANTES for 7 days after renal transplantation in rats improved chronic transplant function with reduced proteinuria, glomerulosclerosis, and interstitial fibrosis after 28 weeks [71]. As leukocytes expressing the CCL5/RANTES receptor CCR5 are frequently found in interstitial cell infiltrates of human renal transplants $[41,72]$, these data may also be relevant to human transplant nephropathy. The strongest support for this hypothesis comes from a multicenter case-control study in human renal transplant recipients [73]. In humans, a 32 -bp deletion $(\Delta 32)$ in the CCR5 gene generates a nonfunctional receptor, with a homozygous prevalence of about $1 \%$ in the Caucasian population. These $\Delta 32$ homo- zygotes show no apparent phenotype. When the influence of the $\Delta 32$ mutation of CCR 5 was analyzed in over 570 renal transplant recipients, long-term graft survival was significantly better in the homozygous $\Delta 32$ CCR 5 group compared to either the heterozygote or wild-type transplant recipients, suggesting a pathophysiological role of CCR5 in transplant nephropathy [73]. Of note, the number of acute rejections was not influenced by the $\Delta 32$ mutation of CCR5 in this study. As chronic allograft nephropathy emerges as a major problem in renal transplantation, the potential role of CCR5-positive leukocytes in this process may be of special interest. Possibly CCR5positive cells in the transplant may play a role in the process of chronic transplant nephropathy. A detailed analysis of various chemokine receptor polymorphisms in human renal transplant recipients revealed another mutation of CCR5 (homozygous for the 59029-A allele) as well as a CCR2 deletion (CCR2-64I allele) which significantly reduced the frequency of acute rejection episodes [74]. However, a recent study by other investigators could not find a protective effect of the CCR2-64I allele in acute or chronic rejection [75]. One problem with such association studies may lie in the relative small numbers of cases examined, which may lack adequate statistical power to come to valid conclusions. Interestingly, Kruger et al. [75] did demonstrate a higher risk for premature kidney graft failure in transplant recipients homozygous for the CCL2/ MCP-1 mutation 2518G. Peripheral blood mononuclear cells isolated from these patients were characterized by a 2.5-fold higher CCL2/MCP-1 secretion, which may augment CCL2/MCP-1-dependent leukocyte recruitment and activation into the allograft.

These data suggest that chemokine-mediated leukocyte influx and activation play both roles in acute rejection and in chronic transplant nephropathy. Particularly CCR5 may be a promising target for therapeutic intervention to prevent progression of chronic transplant loss, especially as the absence of functional CCR 5 in humans is not associated with any deleterious phenotype.

\section{Chemokines in the Progression of Renal Disease}

Several recent studies, including work from our own laboratory, evaluated the role of chemokines in the progression of renal disease. As the glomerular and interstitial infiltrate in chronic nephropathies mainly consists of macrophages and $\mathrm{T}$ cells, these studies focused on chemokines predominantly targeting mononuclear cells, that is 
$\mathrm{CC}$ chemokines, and their receptors. Progression of various chronic nephropathies to end-stage renal disease correlates best with progressive tubulointerstitial injury and renal fibrosis $[13,76]$. The accumulation of interstitial leukocytes as a major source of proinflammatory and profibrotic cytokines is critical for this process, characterized by tubular damage, interstitial fibroblast accumulation and matrix deposition. Blocking the chemokine-mediated recruitment and activation of interstitial leukocytes may therefore be a potential therapeutic strategy for progressive renal disease independent of the primary lesion.

\section{Targeting CCR1 Ameliorates Interstitial}

\section{Inflammation and Fibrosis}

We have recently shown that blockade of the $\mathrm{CC}$ chemokine receptor CCR1 with the small molecule antagonist BX471 substantially reduced interstitial leukocyte infiltration, interstitial fibroblast accumulation, and interstitial matrix deposition in murine obstructive nephropathy as a model of progressive interstitial inflammation and fibrosis [77]. Importantly, blockade of CCR 1 at a later time point, when significant tubulointerstitial injury was already present, was effective in reducing the disease progression [77]. A role for CCR 1 in mediating leukocyte recruitment and interstitial fibrosis was subsequently confirmed by similar studies with CCR1-deficient mice using the same model [78]. Of note, the CC chemokine receptor CCR5 appears not to be instrumental in these processes, as interstitial leukocyte infiltration and markers of renal fibrosis were not altered in CCR5-deficient mice [78]. These studies identified CCR1 as a promising target for reducing interstitial inflammation and fibrosis as major determinants in the progression of chronic nephropathies. Similarly, blockade of CCR1-dependent leukocyte infiltration has been shown to decrease tissue fibrosis in other organs than kidney. Tokuda et al. [79] have developed a polyclonal antibody with blocking activity against CCR1. When given in the mouse model of bleomycin-induced pulmonary fibrosis, a marked reduction of leukocyte infiltrates and interstitial fibrosis was found, which was associated with increased survival of treated mice.

However, as discussed earlier, chemokines are not only involved in local leukocyte recruitment and activation, but are also regulators of systemic immune responses. Thus, data obtained in the obstructive nephropathy model may not apply to renal disease caused by immunemediated mechanisms. We therefore studied the effects of therapeutic CCR1 blockade in the progressive renal injury of lupus-like nephritis in MRL/MPJ FASlpr/pr (MRL/ lpr) mice. In these mice a progressive immune-complex glomerulonephritis with tubulointerstitial disease develops, resulting in end-stage renal failure as in human lupus nephritis. CCR 1 and its chemokine ligands are increasingly expressed in kidneys of MRL/lpr mice [33]. When BX471 treatment to block CCR1 was given late during the course of disease (at 20-24 weeks of age), blood urea nitrogen levels improved, and the extent of interstitial leukocyte infiltration and fibrosis was reduced [80]. Cell transfer studies with labeled macrophages and $\mathrm{T}$ cells that were pretreated with either vehicle or BX471 confirmed the CCR1-dependent recruitment of these cells to the renal interstitium of MRL/lpr mice. In view of the aggravated disease in CCR1-deficient mice with nephrotoxic serum nephritis [62], it is particularly important that blockade of CCR1 in MRL/lpr mice did not affect proteinuria, glomerular injury, and serum levels of DNA autoantibodies, suggesting that CCR1 blockade with BX471 did not alter systemic autoimmunity in these mice. However, these data also indicate that targeting CCR 1 in chronic glomerulonephritidis may not alter the glomerular disease process, in spite of having beneficial effects on the progressive tubulointerstitial inflammation and fibrosis.

Sustained proteinuria is a major prognostic factor for the progression of renal disease [13]. Albumin exposure and tubular intraluminal complement can induce chemokine expression by renal tubular epithelial cells, suggesting that proteinuria may significantly contribute to tubulointerstitial inflammation [81, 82]. We therefore examined the effects of CCR1 blockade with BX471 in murine adriamycin nephropathy, a model of focal segmental glomerulosclerosis with nephrotic syndrome and progressive interstitial fibrosis. BX471 treatment was started at day 14 when proteinuria had already developed. Again, BX471 significantly reduced the number of infiltrating macrophages and $\mathrm{T}$ cells in the interstitium, and markers of renal fibrosis, including interstitial fibroblast accumulation and volume expansion [83]. In contrast, the extent of proteinuria and glomerulosclerosis was not affected by BX471 treatment. These findings together with the data obtained in the MRL/lpr mice demonstrate that the beneficial effects of therapeutic CCR 1 blockade in progressive renal injury are confined to the interstitial compartment, but can occur despite persisting proteinuria.

\section{Blockade of CCL2/MCP-1 and CCR2 May Have \\ Beneficial, but Also Adverse Effects in Progressive \\ Renal Injury}

In addition to CCR 1 , roles of CCL2/MCP-1 and its receptor CCR2 have been identified in animal models of 
progressive nephropathies. Shimizu et al. [84] recently reported that local transfection of a gene construct encoding the CCL2/MCP-1 antagonistic protein 7ND attenuated interstitial macrophage infiltration and tubulointerstitial injury in rats with protein-overload proteinuria. A preliminary report also noted beneficial effects of genetransferred 7ND in murine obstructive nephropathy, where interstitial macrophages and markers of renal fibrosis were reduced [85]. Similar results were obtained using mice genetically deficient for the CCL2/MCP-2 receptor CCR 2 and by blockade of CCR 2 with the inhibitor propagermanium [85].

When CCL2/MCP-1-deficient mice were crossbred with lupus-prone MRL/lpr-mice, lack of CCL2/MCP-1 reduced proteinuria, glomerular and tubulointerstitial pathology, without affects on serum immunoglobulin isotypes or renal immune and complement deposits [32]. Glomerular and interstitial infiltration of macrophages was diminished, and decreased interstitial T-cell infiltrates were noted. Recently, similar results were obtained in MRL/lpr mice treated with a CCL2/MCP-1 antagonist [86]. Although beneficial effects on interstitial disease may be indirect as a consequence of less glomerular damage and proteinuria causing less tubulointerstitial injury, the data clearly suggest a pathophysiologic role of CCL2/ MCP-1-dependent leukocyte infiltrates in murine lupus nephritis. However, these findings differ from earlier data obtained in the nephrotoxic serum nephritis model, where tubulointerstitial, but not glomerular disease was diminished in CCL2/MCP-1-deficient mice with acute glomerulonephritis [56]. Importantly, a recent study reported that lupus nephritis in MRL/lpr mice was aggravated when CCR2 was blocked with a neutralizing antibody. Although proteinuria was unchanged, these mice showed 2- to 3-fold higher numbers of infiltrating renal macrophages and $\mathrm{T}$ cells, and more severe interstitial fibrosis [87]. Plasma cytokine levels for IFN- $\gamma$ and IL-6 were significantly increased. Thus, CCR2 antagonism aggravated both systemic and local inflammatory responses. Preliminary data suggested that blockade of CCR2-positive regulatory $\mathrm{T}$ cells was responsible for this exacerbation [87]. A dual role of CCR2 in chronic inflammatory disease has been recently shown in a model of collageninduced arthritis [88]. CCR2 blockade in the initiation phase of the disease improved clinical signs of arthritis and histological scores including leukocyte infiltration and joint destruction. CCR2 antagonism was associated with a decreased cellular and humoral immune response against collagen, as also noted in MCP-1-deficient mice, possibly due to impaired migration of antigen-presenting cells or direct effects on effector $\mathrm{T}$ cells. However, late onset blockade during the progression phase markedly aggravated arthritis and increased the humoral immunity against collagen. Again, blockade of CCR2-positive regulatory $\mathrm{T}$ cells, which apparently have important roles in down-modulating chronic inflammatory responses, was implicated in this finding [88].

Taken together, available data indicate that CCR 1 and CCL2/CCR2 signaling mediate leukocyte recruitment and renal injury during the progression of chronic nephropathies. Interestingly, it appears that the role of CCR1 is limited to the interstitial compartment, whereas the CCL2/CCR2 system may mediate both glomerular and interstitial leukocyte influx and damage. Importantly, the blockade of CCR2 in more advanced disease may target leukocyte subpopulations with anti-inflammatory properties. This may exacerbate chronic nephropathies instead of improving their outcome. This novel role of chemokine receptors in directing regulatory $\mathrm{T}$ cells opens up an entirely new field of investigation, that is the role of chemokines in regulatory T-cell responses and thus in the modulation of local immune tolerance.

\section{Conclusions for Targeting Chemokines in Renal Disease}

From the above, several new paradigms may evolve for future research in the field of targeting chemokines in chronic inflammation including immune-mediated renal disease:

1. Leukocyte recruitment is only one of many functions of proinflammatory chemokines. For example, immune cell activation is another important function of proinflammatory chemokines such as CCL5/RANTES. In fact, under certain conditions, chemokine antagonists can aggravate glomerulonephritis in spite of efficiently blocking glomerular leukocyte recruitment. This could be mediated by acting as a partial agonist on resident glomerular macrophages [59]. Furthermore, chemokines such as CCL5/RANTES may also be involved in the uptake of apoptotic cells and as such in preventing excessive inflammation. This may also be one problem of the use of CCL5/ RANTES antagonists in acute glomerulonephritis, where apoptosis plays an important role in the resolution of the disease. Additional roles of chemokines and chemokine receptors such as in dendritic cell maturation and in regulatory T-cell trafficking have to be considered as well. Finally, there are independent species differences in the role of chemokines and chemokine receptors. For exam- 


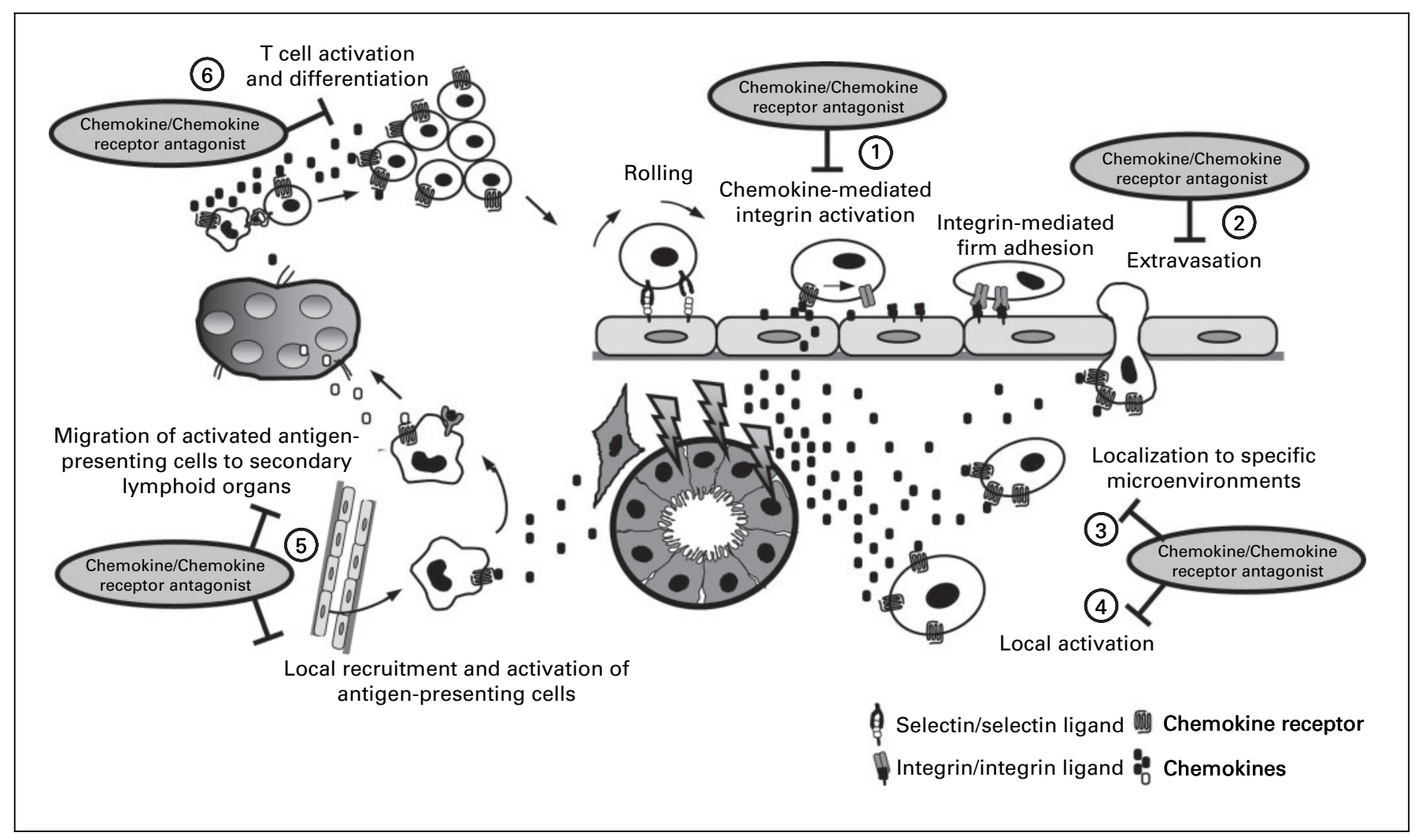

Fig. 2. Potential sites for chemokine antagonists to block renal leukocyte recruitment and activation. Chemokine antagonists may block multiple phases of this process, including chemokine-mediated integrin activation and subsequent firm arrest of the leukocyte to the endothelium (1), transmigration and diapedesis into the interstitium (2), migration along a chemokine gradient and localization within the inflamed microenvironment (3), and chemokinemediated activation of leukocyte effector functions (4). Moreover, chemokine antagonists may alter migration properties of antigen-presenting cells towards inflamed tissue and secondary lymphoid organs (5), and the generation of leukocyte effector cell populations within lymphoid organs (6), resulting in an altered immune response to the initial tissue injury.

ple, CCR2 is present on regulatory $\mathrm{T}$ cells in mice, but not in humans.

2. Chemokine antagonists can have different outcomes in different renal disease models, as shown for MetRANTES which aggravated apoferritin-induced glomerulonephritis in mice [59], but improved acute and chronic renal allograft rejection in rats $[70,71]$. Therefore, each chemokine antagonist must be carefully evaluated in appropriate disease models before being applied in the corresponding clinical settings.

3. Results with knockout mice can only be used in a limited manner to assess the therapeutic potential of chemokine blockade in disease models that involve adaptive immune responses. The evolution of adaptive immunity occurs in different stages that all involve chemokine sig- naling, for example migration of antigen-presenting cells, T-cell differentiation, and effector cell migration into the kidney [6-8]. As it has been shown that blocking certain chemokines or chemokine receptors in different stages of this process can result in opposite outcomes of disease $[87,88]$, knockout mice cannot predict the effect of chemokine blockade in later stages of disease in such models. A conditional gene targeting approach that allows deletion of gene function at a later time point of the disease course may help to circumvent this problem.

Nonetheless, chemokine antagonists may be the most promising approach to assess the therapeutic potential of chemokine or chemokine receptor blockade. However, the specificity of the antagonist for the respective chemokine or chemokine receptor has to be carefully docu- 
mented for the species studied. This includes data on neutralization of biological activity of the respective chemokine or chemokine receptor as well as data that show that neutralization of other chemokines or chemokine receptors of the same class does not occur. In interventional studies one has to make sure that the antagonist used does not interfere with the basic mechanisms of induction of the experimental disease. As the goal should be one of therapeutic intervention, the antagonists should be evaluated once the disease is established. Only the latter provides information about the therapeutic use of the antagonists in progressive diseases, as chronic diseases such as renal failure are usually diagnosed and started on treatment in the progressive phase.

In spite of all the reservations, chemokine and chemokine receptor antagonists may prove to be of considerable therapeutic value, particularly in renal diseases with chronic progression, where infiltrating leukocytes, such as $\mathrm{T}$ cells, macrophages and dendritic cells play a major role. Different phases of the cascade of inflammatory cell recruitment and activation may be influenced by such antagonists resulting in a reduction of inflammatory effector cells in the kidney (fig. 2). The generation of small, orally active inhibitors may allow the evaluation of this hypothesis in the next decade.

\section{Acknowledgements}

This work was supported in part by grants from the Ludwig Maximilians University (FöFoLe 159) to V.V, the Deutsche Akademischer Austauschdienst and the Board of the German Society of Nephrology to V.E., the Deutsche Forschungsgemeinschaft (LU 612/4-1), the German Kidney Foundation, and the Wilhelm Sander Foundation to H.J.A.

\section{References}

1 Rollins BJ: Chemokines. Blood 1997;90:909928.

2 Luster AD: Chemokines - Chemotactic cytokines that mediate inflammation. $\mathrm{N}$ Engl $\mathrm{J}$ Med 1998;338:436-445.

3 Mackay CR: Chemokines: Immunology's high impact factors. Nat Immunol 2001;2:95-101.

4 Campbell JJ, Butcher EC: Chemokines in tissue-specific and microenvironment-specific lymphocyte homing. Curr Opin Immunol 2000; $12: 336-341$

5 Ley K: Arrest chemokines. Microcirculation 2003;10:289-295.

6 Zlotnik A, Yoshie O: Chemokines: A new classification system and their role in immunity. Immunity 2000;12:121-127.

7 Luther SA, Cyster JG: Chemokines as regulators of T-cell differentiation. Nat Immunol 2001;2:102-107.

8 Campbell DJ, Kim CH, Butcher EC: Chemokines in the systemic organization of immunity. Immunol Rev 2003;195:58-71.

9 Keane MP, Strieter RM: The role of CXC chemokines in the regulation of angiogenesis. Chem Immunol 1999;72:86-101.

10 Salcedo R, Oppenheim JJ: Role of chemokines in angiogenesis: CXCL12/SDF-1 and CXCR4 interaction, a key regulator of endothelial cell responses. Microcirculation 2003;10:359-370.

11 Rovin BH: Chemokine blockade as a therapy for renal disease. Curr Opin Nephrol Hypertens 2000;9:225-232.

12 Segerer S, Nelson PJ, Schlöndorff D: Chemokines, chemokine receptors, and renal disease: From basic science to pathophysiologic and therapeutic studies. J Am Soc Nephrol 2000; 11:152-176.
13 Anders HJ, Vielhauer V, Schlöndorff D: Chemokines and chemokine receptors are involved in the resolution or progression of renal disease. Kidney Int 2003;63:401-415.

14 Murphy PM, Baggiolini M, Charo IF, Hebert CA, Horuk R, Matsushima K, Miller LH, Oppenheim JJ, Power CA: International union of pharmacology. XXII. Nomenclature for chemokine receptors. Pharmacol Rev 2000;52: 145-176.

15 Carter PH: Chemokine receptor antagonism as an approach to anti-inflammatory therapy: 'Just right' or plain wrong? Curr Opin Chem Biol 2002; 6:510-525.

16 Weber C, Weber KS, Klier C, Gu S, Wank R, Horuk R, Nelson PJ: Specialized roles of the chemokine receptors CCR1 and CCR5 in the recruitment of monocytes and Th1-like/ CD45RO(+) T cells. Blood 2001;97:11441146.

17 Mellado M, Rodriguez-Frade JM, Vila-Coro AJ, Fernandez S, Martin de Ana A, Jones DR, Toran JL, Martinez-A C: Chemokine receptor homo- or heterodimerization activates distinct signaling pathways. EMBO J 2001;20:24972507.

18 Butcher EC: Leukocyte-endothelial cell recognition: Three (or more) steps to specificity and diversity. Cell 1991;67:1033-1036.

19 Springer TA: Traffic signals for lymphocyte recirculation and leukocyte emigration: The multistep paradigm. Cell 1994;76:301-314.

20 Bevilacqua M, Butcher E, Furie B, Furie B, Gallatin M, Gimbrone M, Harlan J, Kishimoto K, Lasky L, McEver R, et al: Selectins: A family of adhesion receptors. Cell 1991;67:233.

21 Ley K: Molecular mechanisms of leukocyte recruitment in the inflammatory process. Cardiovasc Res 1996;32:733-742.
22 Campbell JJ, Hedrick J, Zlotnik A, Siani MA, Thompson DA, Butcher EC: Chemokines and the arrest of lymphocytes rolling under flow conditions. Science 1998;279:381-384.

23 Laudanna C, Kim JY, Constantin G, Butcher E: Rapid leukocyte integrin activation by chemokines. Immunol Rev 2002;186:37-46.

24 Taub DD, Turcovski-Corrales SM, Key ML, Longo DL, Murphy WJ: Chemokines and T lymphocyte activation. I. Beta chemokines costimulate human $\mathrm{T}$ lymphocyte activation in vitro. J Immunol 1996;156:2095-2103.

25 Moser B, Loetscher P: Lymphocyte traffic control by chemokines. Nat Immunol 2001;2:123128.

26 Gu L, Tseng S, Horner RM, Tam C, Loda M, Rollins BJ: Control of Th2 polarization by the chemokine monocyte chemoattractant protein1. Nature 2000;404:407-411.

27 Anders HJ, Vielhauer V, Kretzler M, Cohen CD, Segerer S, Luckow B, Weller L, Gröne HJ, Schlöndorff D: Chemokine and chemokine receptor expression during initiation and resolution of immune complex glomerulonephritis. J Am Soc Nephrol 2001;12:919-931.

28 Vielhauer V, Anders HJ, Mack M, Cihak J, Strutz F, Stangassinger M, Luckow B, Gröne HJ, Schlöndorff D: Obstructive nephropathy in the mouse: Progressive fibrosis correlates with tubulointerstitial chemokine expression and accumulation of CC chemokine receptor- 2 and -5-positive leukocytes. J Am Soc Nephrol 2001; 12:1173-1187.

29 Wu X, Dolecki GJ, Sherry B, Zagorski J, Lefkowith JB: Chemokines are expressed in a myeloid cell-dependent fashion and mediate distinct functions in immune complex glomerulonephritis in rat. J Immunol 1997;158:39173924 
30 Haberstroh U, Pocock J, Gomez-Guerrero C, Helmchen U, Hamann A, Gutierrez-Ramos JC, Stahl RA, Thaiss F: Expression of the chemokines MCP-1/CCL2 and RANTES/CCL5 is differentially regulated by infiltrating inflammatory cells. Kidney Int 2002;62:1264-1276.

31 Garcia GE, Xia Y, Harrison J, Wilson CB, Johnson RJ, Bacon KB, Feng L: Mononuclear cell-infiltrate inhibition by blocking macrophage-derived chemokine results in attenuation of developing crescentic glomerulonephritis. Am J Pathol 2003;162:1061-1073.

32 Tesch GH, Maifert S, Schwarting A, Rollins BJ, Kelley VR: Monocyte chemoattractant protein-1-dependent leukocytic infiltrates are responsible for autoimmune disease in MRLFas(lpr) mice. J Exp Med 1999;190:18131824.

33 Pérez de Lema G, Maier H, Nieto E, Vielhauer V, Luckow B, Mampaso F, Schlöndorff D: Chemokine expression precedes inflammatory cell infiltration and chemokine receptor and cytokine expression during the initiation of murine lupus nephritis. J Am Soc Nephrol 2001;12: 1369-1382.

34 Anders HJ, Banas B, Linde Y, Weller L, Cohen CD, Kretzler $M$, Martin S, Vielhauer V Schlöndorff D, Gröne HJ: Bacterial CpG-DNA aggravates immune complex glomerulonephritis: Role of TLR9-mediated expression of chemokines and chemokine receptors. J Am Soc Nephrol 2003;14:317-326.

35 Anders HJ, Vielhauer V, Eis V, Linde Y, Kretzler M, Pérez de Lema G, Strutz F, Bauer S, Rutz M, Wagner H, Gröne HJ, Schlöndorff D: Activation of toll-like receptor-9 induces progression of renal disease in MRL(Fas)lpr mice. Faseb J 2004; 18:534-536.

36 Cockwell P, Howie AJ, Adu D, Savage COS: In situ analysis of C-C chemokine mRNA in human glomerulonephritis. Kidney Int 1998;54: 827-836.

37 Romagnani P, Beltrame C, Annunziato F, Lasagni L, Luconi M, Galli G, Cosmi L, Maggi E, Salvadori M, Pupilli C, Serio M: Role for interactions between IP-10/Mig and CXCR 3 in proliferative glomerulonephritis. J Am Soc Nephrol 1999; 10:2518-2526.

38 Segerer S, Cui Y, Hudkins KL, Goodpaster T, Eitner F, Mack M, Schlöndorff D, Alpers CE: Expression of the chemokine monocyte chemoattractant protein- 1 and its receptor chemokine receptor- 2 in human crescentic glomerulonephritis. J Am Soc Nephrol 2000;11:22312242

39 Liu ZH, Chen SF, Zhou H, Chen HP, Li LS: Glomerular expression of $\mathrm{C}-\mathrm{C}$ chemokines in different types of human crescentic glomerulonephritis. Nephrol Dial Transplant 2003;18: 1526-1534.

40 Cockwell P, Chakravorty SJ, Girdlestone J, Savage CO: Fractalkine expression in human renal inflammation. J Pathol 2002;196:85-90.

41 Segerer S, Mack M, Regele H, Kerjaschki D, Schlondorff D: Expression of the C-C chemokine receptor 5 in human kidney diseases. Kidney Int 1999;56:52-64.
42 Segerer S, Hughes E, Hudkins KL, Mack M, Goodpaster T, Alpers CE: Expression of the fractalkine receptor (CX3CR1) in human kidney diseases. Kidney Int 2002;62:488-495.

43 Furuichi K, Wada T, Sakai N, Iwata Y, Yoshimoto K, Shimizu M, Kobayashi K, Takasawa K, Kida H, Takeda SI, Mukaida N, Matsushima K, Yokoyama H: Distinct expression of CCR 1 and CCR 5 in glomerular and interstitial lesions of human glomerular diseases. Am J Nephrol 2000;20:291-299.

44 Wu X, Wittwer AJ, Carr LS, Crippes BA, DeLarco JE, Lefkowith JB: Cytokine-induced neutrophil chemoattractant mediates neutrophil influx in immune complex glomerulonephritis in rat. J Clin Invest 1994;94:337-344.

45 Feng L, Xia Y, Yoshimura T, Wilson CB: Modulation of neutrophil influx in glomerulonephritis in the rat with anti-macrophage inflammatory protein-2 (MIP-2) antibody. J Clin Invest 1995;95:1009-1017.

46 Zernecke A, Weber KS, Erwig LP, Kluth DC, Schroppel B, Rees AJ, Weber C: Combinatorial model of chemokine involvement in glomerular monocyte recruitment: Role of CXC chemokine receptor-2 in infiltration during nephrotoxic nephritis. J Immunol 2001;166:57555762.

47 Chen S, Bacon KB, Li L, Garcia GE, Xia Y, Lo D, Thompson DA, Siani MA, Yamamoto T, Harrison JK, Feng L: In vivo inhibition of CC and $\mathrm{CX} 3 \mathrm{C}$ chemokine-induced leukocyte infiltration and attenuation of glomerulonephritis in Wistar-Kyoto rats by vMIP-II. J Exp Med 1998;188:193-198.

48 Feng L, Chen S, Garcia GE, Xia Y, Siani MA, Botti P, Wilson CB, Harrison JK, Bacon KB: Prevention of crescentic glomerulonephritis by immunoneutralization of the fractalkine receptor CX3CR 1 rapid communication. Kidney Int 1999;56:612-620.

49 Wenzel U, Schneider A, Valente AJ, Abboud HE, Thaiss F, Helmchen UM, Stahl RAK: Monocyte chemoattractant protein-1 mediates monocyte/macrophage influx in anti-thymocyte antibody-induced glomerulonephritis. Kidney Int 1997;51:770-776.

50 Tang WW, Qi M, Warren JS: Monocyte chemoattractant protein-1 mediates glomerular macrophage infiltration in anti-GBM Ab GN. Kidney Int 1996;50:665-671.

51 Wada T, Yokoyama H, Furuichi K, Kobayashi KI, Harada K, Naruto M, Su SB, Akiyama M, Mukaida N, Matsushima K: Intervention of crescentic glomerulonephritis by antibodies to monocyte chemotactic and activating factor (MCAF/MCP-1). Faseb J 1996;10:1418-1425.

52 Fujinaka H, Yamamoto T, Takeya M, Feng L, Kawasaki K, Yaoita E, Kondo D, Wilson CB, Uchiyama M, Kihara I: Suppression of antiglomerular basement membrane nephritis by administration of anti-monocyte chemoattractant protein-1 antibody in WKY rats. J Am Soc Nephrol 1997;8:1174-1178.
53 Lloyd CM, Minto AW, Dorf ME, Proudfoot A, Wells TN, Salant DJ, Gutierrez-Ramos JC: RANTES and monocyte chemoattractant protein-1 (MCP-1) play an important role in the inflammatory phase of crescentic nephritis, but only MCP-1 is involved in crescent formation and interstitial fibrosis. J Exp Med 1997;185: 1371-1380.

54 Iwata $\mathrm{Y}$, Wada $\mathrm{T}$, Furuichi $\mathrm{K}$, Ishiwata $\mathrm{Y}$, Yokoyama H: CCR2 inhibition ameliorates rat crescentic glomerulonephritis (abstract). J Am Soc Nephrol 2003;14:169A.

55 Okada H, Moriwaki K, Kalluri R, Imai H, Ban S, Takahama M, Suzuki H: Inhibition of monocyte chemoattractant protein-1 expression in tubular epithelium attenuates tubulointerstitial alteration in rat Goodpasture syndrome. Kidney Int 2000;57:927-936.

56 Tesch GH, Schwarting A, Kinoshita K, Lan HY, Rollins BJ, Kelley VR: Monocyte chemoattractant protein-1 promotes macrophagemediated tubular injury, but not glomerular injury, in nephrotoxic serum nephritis. J Clin Invest 1999;103:73-80.

57 Bird JE, Giancarli MR, Kurihara T, Kowala MC, Valentine MT, Gitlitz PH, Pandya DG, French $\mathrm{MH}$, Durham SK: Increased severity of glomerulonephritis in C-C chemokine receptor-2 knockout mice. Kidney Int 2000;57:129_ 136.

58 Panzer U, Schneider A, Wilken J, Thompson DA, Kent SB, Stahl RA: The chemokine receptor antagonist AOP-RANTES reduces monocyte infiltration in experimental glomerulonephritis. Kidney Int 1999;56:2107-2115.

59 Anders HJ, Frink M, Linde Y, Banas B, Wörnle M, Cohen CD, Vielhauer V, Nelson PJ, Gröne HJ, Schlöndorff D: CC chemokine ligand 5/RANTES chemokine antagonists aggravate glomerulonephritis despite reduction of glomerular leukocyte infiltration. J Immunol 2003; 170:5658-5666.

60 Proudfoot AE, Buser R, Borlat F, Alouani S, Soler D, Offord RE, Schroder JM, Power CA, Wells TN: Amino-terminally modified RANTES analogues demonstrate differential effects on RANTES receptors. J Biol Chem 1999;274:32478-32485.

61 Fituri O, Shemmeri N, Salant D, Hancock WW: Targeting of chemokine receptor CCR5 does not protect against renal injury in murine nephrotoxic nephritis (NTN) (abstract). J Am Soc Nephrol 2000;11:488A.

62 Topham PS, Csizmadia V, Soler D, Hines D, Gerard CJ, Salant DJ, Hancock WW: Lack of chemokine receptor CCR1 enhances Th1 responses and glomerular injury during nephrotoxic nephritis. J Clin Invest 1999;104:15491557.

63 Furuichi K, Wada T, Yokoyama H, Kobayashi KI: Role of cytokines and chemokines in renal ischemia-reperfusion injury. Drug News Perspect 2002;15:477-482.

64 Miura M, Fu X, Zhang QW, Remick DG, Fairchild RL: Neutralization of Gro- $\alpha$ and macrophage inflammatory protein- 2 attenuates renal ischemia/reperfusion injury. Am $\mathrm{J}$ Pathol 2001;159:2137-2145 
65 Furuichi K, Wada T, Iwata Y, Kitagawa K, Kobayashi K, Hashimoto H, Ishiwata Y, Asano M, Wang H, Matsushima K, Takeya M, Kuziel WA, Mukaida N, Yokoyama H: CCR2 signaling contributes to ischemia-reperfusion injury in kidney. J Am Soc Nephrol 2003;14: 2503-2515.

66 Furuichi K, Wada T, Iwata Y, Kitagawa K, Kobayashi K, Hashimoto H, Ishiwata Y, Tomosugi N, Mukaida N, Matsushima K, Egashira $\mathrm{K}$, Yokoyama $\mathrm{H}$ : Gene therapy expressing amino-terminal truncated monocyte chemoattractant protein-1 prevents renal ischemia-reperfusion injury. J Am Soc Nephrol 2003;14: 1066-1071.

67 Rabb H: The T cell as a bridge between innate and adaptive immune systems: Implications for the kidney. Kidney Int 2002;61:19351946.

68 Burne-Taney MJ, Ascon DB, Daniels F, Racusen L, Baldwin W, Rabb H: B-cell deficiency confers protection from renal ischemia reperfusion injury. J Immunol 2003;171:3210-3215.

69 Horuk R, Shurey S, Ng HP, May K, Bauman JG, Islam I, Ghannam A, Buckman B, Wei GP, Xu W, Liang M, Rosser M, Dunning L, Hesselgesser J, Snider RM, Morrissey MM, Perez HD, Green C: CCR1-specific non-peptide antagonist: Efficacy in a rabbit allograft rejection model. Immunol Lett 2001;76:193-201.

70 Gröne HJ, Weber C, Weber KS, Gröne EF Rabelink T, Klier CM, Wells TN, Proudfood AE, Schlöndorff D, Nelson PJ: Met-RANTES reduces vascular and tubular damage during acute renal transplant rejection: Blocking monocyte arrest and recruitment. FASEB J 1999; 13:1371-1383.

71 Song E, Zou H, Yao Y, Proudfoot A, Antus B, Liu S, Jens L, Heemann U: Early application of Met-RANTES ameliorates chronic allograft nephropathy. Kidney Int 2002;61:676-685.

72 Segerer S, Cui Y, Eitner F, Goodpaster T, Hudkins KL, Mack M, Cartron JP, Colin Y, Schlöndorff D, Alpers CE: Expression of chemokines and chemokine receptors during human renal transplant rejection. Am J Kidney Dis 2001;37: 518-531.
73 Fischereder M, Luckow B, Hocher B, Wuthrich RP, Rothenpieler U, Schneeberger H, Panzer U, Stahl RA, Hauser IA, Budde K, Neumayer H, Kramer BK, Land W, Schlöndorff D: CC chemokine receptor-5 and renal-transplant survival. Lancet 2001;357:1758-1761.

74 Abdi R, Tran TB, Sahagun-Ruiz A, Murphy PM, Brenner BM, Milford EL, McDermott DH: Chemokine receptor polymorphism and risk of acute rejection in human renal transplantation. J Am Soc Nephrol 2002;13:754758.

75 Kruger B, Schröppel B, Ashkan R, Marder B, Zulke C, Murphy B, Kramer BK, Fischereder M: A monocyte chemoattractant protein-1 polymorphism and outcome after renal transplantation. J Am Soc Nephrol 2002;13:25852589.

76 Nath KA: Tubulointerstitial changes as a major determinant in the progression of renal damage. Am J Kidney Dis 1992;20:1-17.

77 Anders HJ, Vielhauer V, Frink M, Linde Y, Cohen CD, Blattner SM, Kretzler M, Strutz F, Mack M, Gröne HJ, Onuffer J, Horuk R, Nelson PJ, Schlöndorff D: A chemokine receptor CCR-1 antagonist reduces renal fibrosis after unilateral ureter ligation. J Clin Invest 2002; 109:251-259.

78 Eis V, Luckow B, Vielhauer V, Sieveke J, Linde Y, Segerer S, Pérez de Lema G, Cohen CD, Kretzler M, Mack M, Horuk R, Murphy PM, Gao JL, Hudkins KL, Alpers CE, Gröne HJ, Schlöndorff D, Anders HJ: Chemokine receptor CCR1 but not CCR5 mediates leukocyte recruitment and subsequent renal fibrosis after unilateral ureteral obstruction. J Am Soc Nephrol 2004; 15:337-347.

79 Tokuda A, Itakura M, Onai N, Kimura H, Kuriyama T, Matsushima K: Pivotal role of CCR1-positive leukocytes in bleomycin-induced lung fibrosis in mice. J Immunol 2000; 164:2745-2751.

80 Anders HJ, Belemezova E, Eis V, Segerer S, Vielhauer V, Perez de Lema G, Kretzler M, Cohen CD, Frink M, Horuk R, Hudkins KL, Alpers CE, Mampaso F, Schlöndorff D: Late onset of treatment with a chemokine receptor CCR 1 antagonist prevents progression of lupus nephritis in MRL-Fas(lpr) mice. J Am Soc Nephrol 2004;15:1504-1513.
81 Zoja C, Donadelli R, Colleoni S, Figliuzzi M, Bonazzola S, Morigi M, Remuzzi G: Protein overload stimulates RANTES production by proximal tubular cells depending on $\mathrm{NF}-\kappa \mathrm{B}$ activation. Kidney Int 1998;53:1608-1615.

82 Wang Y, Rangan GK, Tay YC, Wang Y, Harris DC: Induction of monocyte chemoattractant protein-1 by albumin is mediated by nuclear factor- $\kappa \mathrm{B}$ in proximal tubule cells. J Am Soc Nephrol 1999;10:1204-1213.

83 Vielhauer V, Berning E, Linde Y, Kretzler M, Strutz F, Horuk R, Gröne HJ, Schlöndorff D, Anders HJ: A CCR1 antagonist reduces interstitial nephritis and fibrosis, but not proteinuria and glomerular pathology in murine adriamycin nephropathy (abstract). J Am Soc Nephrol 2003;14:167A.

84 Shimizu H, Maruyama S, Yuzawa Y, Kato T, Miki Y, Suzuki S, Sato W, Morita Y, Maruyama H, Egashira K, Matsuo S: Anti-monocyte chemoattractant protein-1 gene therapy attenuates renal injury induced by protein-overload proteinuria. J Am Soc Nephrol 2003;14:14961505.

85 Kitagawa K, Wada T, Furuichi K, Iwata Y, Mukaida N, Mastushima K, Yokoyama $\mathrm{H}$ : Role of MCP-1/CCR2 signaling in progressive renal fibrosis (abstract). J Am Soc Nephrol 2003; 14:593A.

86 Hasegawa H, Kohno M, Sasaki M, Inoue A, Ito MR, Terada M, Hieshima K, Maruyama H, Miyazaki J, Yoshie O, Nose M, Fujita S: Antagonist of monocyte chemoattractant protein-1 ameliorates the initiation and progression of lupus nephritis and renal vasculitis in MRL/lpr mice. Arthritis Rheum 2003;48:2555-2566.

87 Mack M, Schneider M, Pérez de Lema G, Segerer S, Mampaso F, Schlöndorff D: Blockade of the chemokine receptor CCR2 aggravates lupus nephritis in MRL-lpr mice - Evidence for involvement of regulatory $T$ cells ( $a b-$ stract). J Am Soc Nephrol 2003;14:174A.

88 Brühl H, Cihak J, Schneider MA, Plachy J, Rupp T, Wenzel I, Shakarami M, Milz S, Ellwart JW, Stangassinger M, Schlöndorff D, Mack M: Dual role of CCR2 during initiation and progression of collagen-induced arthritis: Evidence for regulatory activity of CCR2(+) T cells. J Immunol 2004;172:890-898. 